\title{
Electrochemical Properties of Gold Incorporated Inside FSM-16 and Y Zeolites
}

\author{
Ibrahim Mekkawy ${ }^{1}$ and Mohamed Mokhtar Mohamed ${ }^{2}$ \\ ${ }^{1}$ Physics Department, Faculty of Science, Al-Azhar University, Assiut branch, Assiut, Egypt \\ ${ }^{2}$ Chemistry Department, Faculty of Science, Zagazig University, Benha branch, Benha, Egypt
}

The $d c$ and ac conductivities as well as the dielectric constant $(\varepsilon)$ were measured for different zeolites encapsulated gold $\left(\mathrm{Au} \mathrm{Cl}_{3}\right)$ catalysts at different temperatures $(300-500 \mathrm{~K})$ as a function of frequency $(5 \mathrm{kHz}-1 \mathrm{MHz})$. The conductivity values were found to be in the order Au/FSM-27 >Au/NaY > Au/FSM47. This result was confirmed by finding that the first ionization energy of $\mathrm{Na}^{+}$ions was much lower than that of $\mathrm{Cl}$ ones. The conductivity of Au either in FSM-27 or FSM-47 was expected to be of electronic character where the hopping mechanism is the most predominant. Whereas, in the case of $\mathrm{Au} / \mathrm{NaY}$; containing $\mathrm{Na}$ and $\mathrm{Cl}$ ions, the conductivity was partially ionic partially electronic. Above $376 \mathrm{~K}$, a metallic behavior was obtained for Au catalysts. The IR study showed that the exposure of $\mathrm{Au}$ zeolites to $\mathrm{CO}$ adsorption produced a characteristic band of $\mathrm{Au}^{+}$$\mathrm{CO}$ at $2180 \mathrm{~cm}^{-1}$ that tends to decrease with temperatures and even vanish at $376 \mathrm{~K}$ in favor of the $A u^{\circ}-\mathrm{CO}$ band at $2128 \mathrm{~cm}^{-1}$. Similarly, a phase transition at $338 \mathrm{~K}$ that extends to $376 \mathrm{~K}$ was confirmed by DTA to further emphasize the temperature region of the metallic Au formation. After the phase transition, the increase in thermal energy caused an increase in the lattice scattering of the charge carriers that produced a decrease in the mobility, polarizability and permitivity. 


\section{Introduction:}

Electrical properties of dielectrics and semiconductors are of great interest because of their wide use in modern electronic devices [1-6]. The electrical properties of these materials depend not only on the chemical composition and structural features but also on the preparation conditions [7-8]. On the other hand, dielectric investigations provide a fundamental way for studying the rotation of dipoles and hopping electron processes involved in conduction [9].

Recently, gold has attracted a high attention as a catalyst or sensor especially when it's encapsulated inside zeolites. Major research in intrazeolitic gold catalysts explored high catalytic activities towards some reactions [10-11]. This was due to the exhibited high dispersion of $\mathrm{Au}^{+}$species inside zeolites. It has been reported that $\mathrm{Au}$ can be incorporated inside zeolites by means of chemical vapor deposition (CVD) method with controlled particle sizes in the range 3-20 nm [12]. Accordingly, the particular interest nowadays in the nanotechnology; because of trying to apply it in different areas such as semiconductors, chem-bio-engineering and sensors, urged us to study the electrical as well as the chemical properties of $\mathrm{AuCl}_{3}$ when encapsulated inside $\mathrm{NaY}$ zeolite or inside some zeolite like structure such as FSM-16.

\section{Experimental: \\ Material preparation}

The host FSM-16 was synthesized using a layered polysilicate and $\mathrm{C}_{16} \mathrm{H}_{33} \mathrm{Nme}_{3} \mathrm{Cl}$ as a micelle surfactant template, similar to MCM-41. This material presents ordered hexagonal channels of varying diameters depend on the surfactant chain length. The $2.5 \mathrm{wt} \% \mathrm{Au} / \mathrm{NaY}$ (Linde Zeolite $\mathrm{NaY}$ of Lot.No. 030785 was used as a starting material), $2.5 \mathrm{wt} \% \mathrm{Au} / \mathrm{FSM}-27$ and 2.5 $\mathrm{wt} \% \mathrm{Au} / \mathrm{FSM}-47$ samples were prepared at room temperature by careful mechanical mixing of Spec. Pure Chemicals (Union Carbide Company) with partially dehydrated NaY, FSM-27 and FSM-47 zeolites, respectively, under a nitrogen atmosphere. The samples were evacuated in a conventional high vacuum $\left(10^{-6}\right.$ Torr $)$ manifold while slowly ramping the temperature $\left(0.2 \mathrm{~K} \mathrm{~min}^{-1}\right)$ up to $388 \mathrm{~K}$, where the exchange reaction was conducted for $48 \mathrm{~h}$. The $\mathrm{AuCl}_{3}$ were slowly vaporized and migrated to interact with water molecules in the zeolites pores or channels [11]. The physiochemical properties of the used Zeolites were presented in Table (1) 
Table (1): Physicochemical properties of the used zeolites

\begin{tabular}{|c|c|c|c|}
\hline Zeolite type & $\begin{array}{c}\text { Si/Al } \\
\text { ratio }\end{array}$ & $\begin{array}{c}\text { Surface area } \\
\left(\mathbf{m}^{2} \mathbf{g}^{-1}\right)\end{array}$ & $\begin{array}{c}\text { Pore size }(\AA) \text { and } \\
\text { (its structure) }\end{array}$ \\
\hline $\begin{array}{r}\text { FSM-16_ } \\
\text { (Mesoporous) }\end{array}$ & 300 & 950 & 27 (channels) \\
& & & \\
NaY (microporous) & 5.6 & 850 & 7.5 (cages) \\
\hline
\end{tabular}

\section{Techniques \\ The FTIR study}

The infrared spectra of $\mathrm{CO}$ adsorption for the samples were recorded with a Jasco double beam FTIR-5300 spectrometer with 40 coadded scans at $4 \mathrm{~cm}^{-1}$ resolution. The sample was pressed into a self-supporting wafer and mounted in a quartz infrared cell and subjected to treatment under vacuum $\left(10^{-4}, 323 \mathrm{~K}\right)$ prior to the $\mathrm{CO}$ admission.

\section{Thermal analysis}

The samples were subjected to thermogravimetry (TG) as well as differential thermal analysis (DTA) over the temperature range from ambient to $873 \mathrm{~K}$ at a heating rate of $10 \mathrm{~K} \mathrm{~min}^{-1}$ under dry air $\left(40 \mathrm{~cm}^{3} \mathrm{~min}^{-1}\right)$. The TG and DTA curves were automatically recorded on a model 50 Shimadzu unit.

\section{Conductivity measurements}

The d.c and a.c electrical conductivity measurements as well as the dielectric constant were carried out using the two-probes method. Silver paste electrical contacts were applied to the flat surfaces of the pellet of $10 \mathrm{~mm}$ diameter and $0.5 \mathrm{~mm}$ thickness. The a.c conductivity $\left(\sigma_{\mathrm{acc}}\right)$ and the real dielectric constant $(\varepsilon)$ were measured at different temperatures $(300-500 \mathrm{~K})$ as a function of the applied frequency $(5 \mathrm{kHz}-1 \mathrm{MHz})$ using Hioki bridge type 3530 (Japan). The d.c conductivity was measured using Keithly electrometer type 416 (USA). T-type thermocouple was used to measure the temperature with it junction just in contact with the sample to avoid ant temperature gradient. The accuracy of measuring temperature was better than $1 \mathrm{~K}$. 


\section{Results and discussion:}

Figure 1 shows the d.c conductivity curves (ln $\sigma$ vs. reciprocal of absolute temperature) for different zeolite samples encapsulated gold catalysts. From the figure, it can be seen that different straight lines were obtained with different activation energies depending on varying the zeolite substrate. It is obvious that the gold catalyst, in the $2.5 \mathrm{wt} \% \mathrm{Au} / \mathrm{FSM}-27$ sample, showed the highest activation energy corresponding to lowest conductivity whereas the $\mathrm{Au} / \mathrm{NaY}$ sample exhibited the lowest activation energy with maximum conductivity. On the other hand, the Au/FSM-47 sample showed moderate activation energy with low conductivity values. This dramatic result can be confirmed by the values of the first ionization energy of $\mathrm{Cl}$ and $\mathrm{Na}$ ions, which were found to equal 300 and $119 \mathrm{~K} \mathrm{cal} / \mathrm{gm}$ mol, respectively. The conductivity of $\mathrm{Au}$ catalyst was expected to be of electronic character where the hopping mechanism is the most predominant, while in case of $\mathrm{NaY}$ containing $\mathrm{Na}$ and $\mathrm{Cl}$ ions, it was considered to be partially ionic partially electronic in conjunction with each other. It should be mentioned that the dispersion of Au species (13.5 $\mathrm{nm}$ ) inside $\mathrm{NaY}$ cages was considerably higher than those in FSM

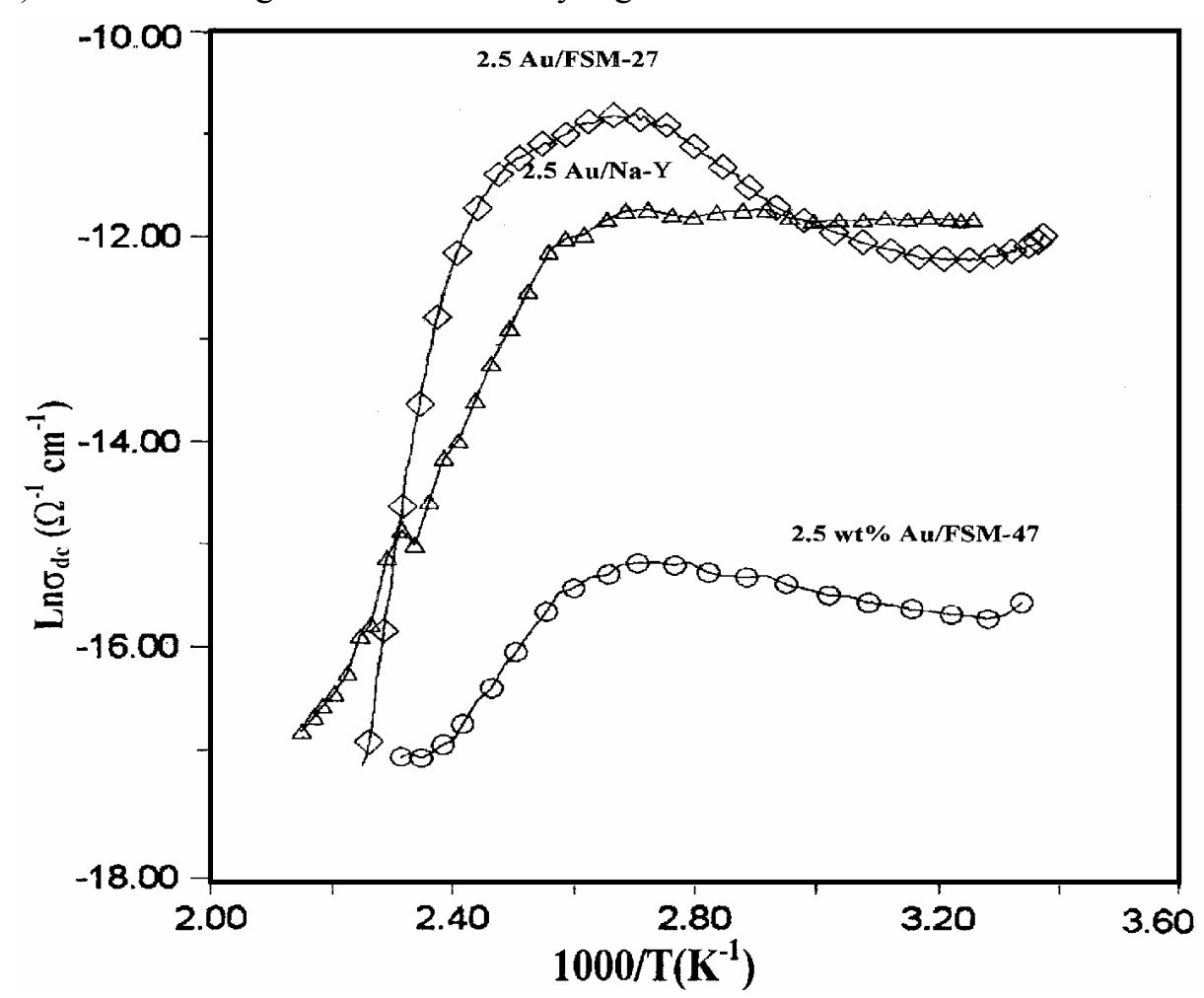

Fig. (1): Dependence of d.c conductivity on inverse temperature for the 2.5 $\mathrm{wt} \% \mathrm{Au} / \mathrm{FSM}-27,2.5 \mathrm{wt} \% \mathrm{Au} / \mathrm{NaY}$ and $2.5 \mathrm{wt} \% \mathrm{Au} / \mathrm{FSM} 47$. 
channels $(25 \mathrm{~nm})$, as has been validated by XRD measurements. This could be another plausible explanation for improving the conductivity of $\mathrm{Au}$ in the former than that in the latter. The transition (peak) that obtained at $376 \mathrm{~K}$ can be explained on the basis of changing conductivity from semiconducting to metallic behavior. Above $376 \mathrm{~K}$, an obvious metallic behavior was attained for the three catalysts which can be interpreted as follows;

$$
3 \mathrm{Au}^{+} \rightarrow 2 \mathrm{Au}^{0}+\mathrm{Au}^{3+}
$$

Figure 2 correlates the a.c conductivity curves ( $\operatorname{Ln} \sigma$ vs. reciprocal of absolute temp.) of the $\mathrm{Aucl}_{3} / \mathrm{FSM}-47$ sample at different frequencies. From the figure, it is clear that more than one straight line is obtained with different activation energy depending on the value of the applied frequency. At certain frequency and by increasing temperature three regions were obtained. The first one was from room temperature up to $338 \mathrm{~K}$, in which the conductivity increases with increasing temperature, that is the general trend of a dielectric material $\left(\mathrm{AuCl}_{3} / \mathrm{FSM}-47\right)$. This may be due to either thermally activated mobility of charge carrier or thermally activated number of the same carrier, or due to the cooperation of the two processes with each other. The second region was from 338 to $417 \mathrm{~K}$ in which the conductivity was slightly decreased. In the

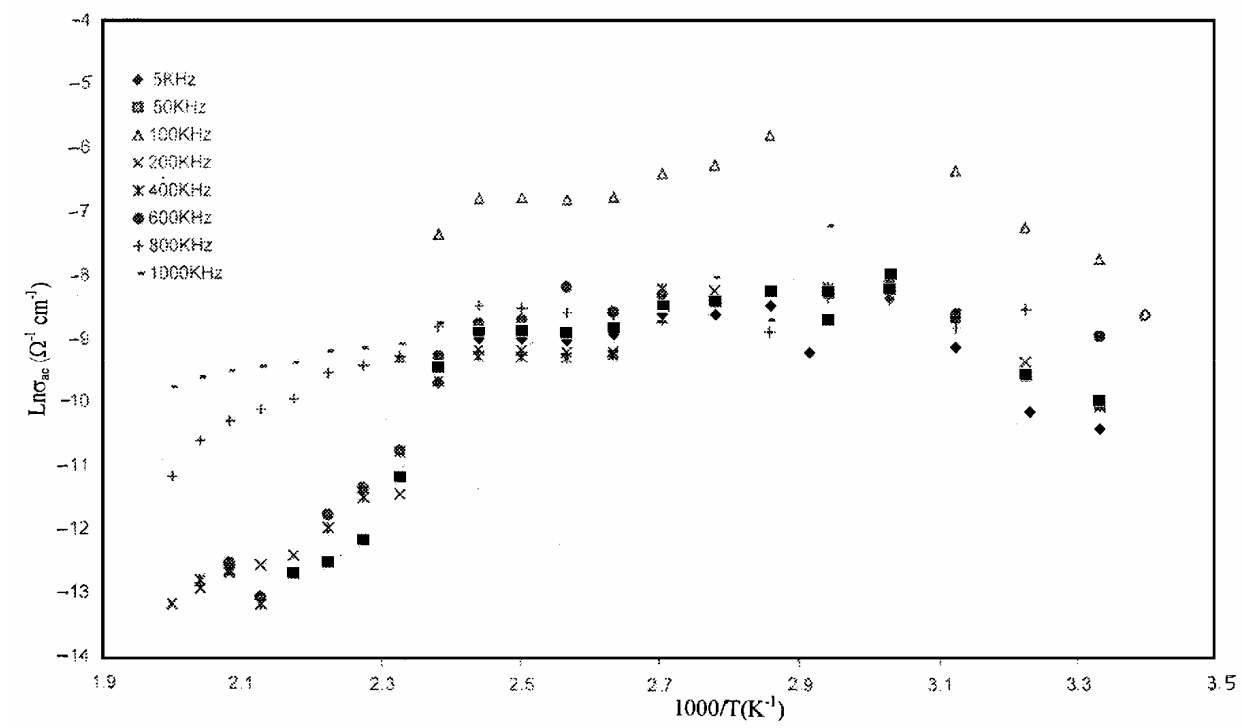

Fig. (2): Dependence of a.c conductivity on inverse temperature for the $2.5 \mathrm{wt} \%$ $\mathrm{Au} / \mathrm{FSM} 47$ sample at different frequencies.

high temperature region, from 417 to $500 \mathrm{~K}$, the conductivity is dramatically decreased. This can be attributed to the production of metallic gold atoms according to the above equation and thus reduce the charge carrier concentration. This is together with thermal scattering taking place with increasing temperature. Such processes give rise to the observed decrease in 
conductivity. With respect to the frequency, it is clear that increasing the frequency from $5 \mathrm{kHz}$ to $100 \mathrm{kHz}$ causes an increase in the activation energy from 2.70 to $6.1 \mathrm{eV}$, respectively. This means that the frequency acts as a disturbing factor affecting aligned dipoles in the field direction. In other words, the charge carriers can not follow up the field variation that accompanies the applied frequency.

The dependence of the dielectric constant $\left(\varepsilon^{\prime}\right)$ on absolute temperature as a function of the applied frequency was shown in Figure 3. The general trend of the figure is the increase in $\dot{\varepsilon}$ with temperature, reaching a maximum value around $330 \mathrm{~K}$, which was consistent with that in the range $323-328 \mathrm{~K}$ brought about by means of DTA thermograms Fig.(4). This point was indicated as a phase transition point. This was confirmed by the weight loss in TGA curves for the FSM-27 sample (not shown) was equivalent to that of Au/FSM-47, implying that the desorption of water contained inside the channels was responsible for the weight change in TG curves and not the Au catalyst. After this point $\dot{\varepsilon}$ decreases sharply to $390 \mathrm{~K}$ after which a slight decrease was attained. In the first part of the graph in Fig.(3), the increase in dielectric constant is due to the increase in polarizability. It can be seen that the small thermal energy, in the latter part, was quiet sufficient to liberate some of the localized dipoles, and the field accompanied with the applied frequency orient them in its direction. The result of this process is the increase in $\dot{\varepsilon}$. After the phase transition, the increase in thermal energy causes an increase in the lattice

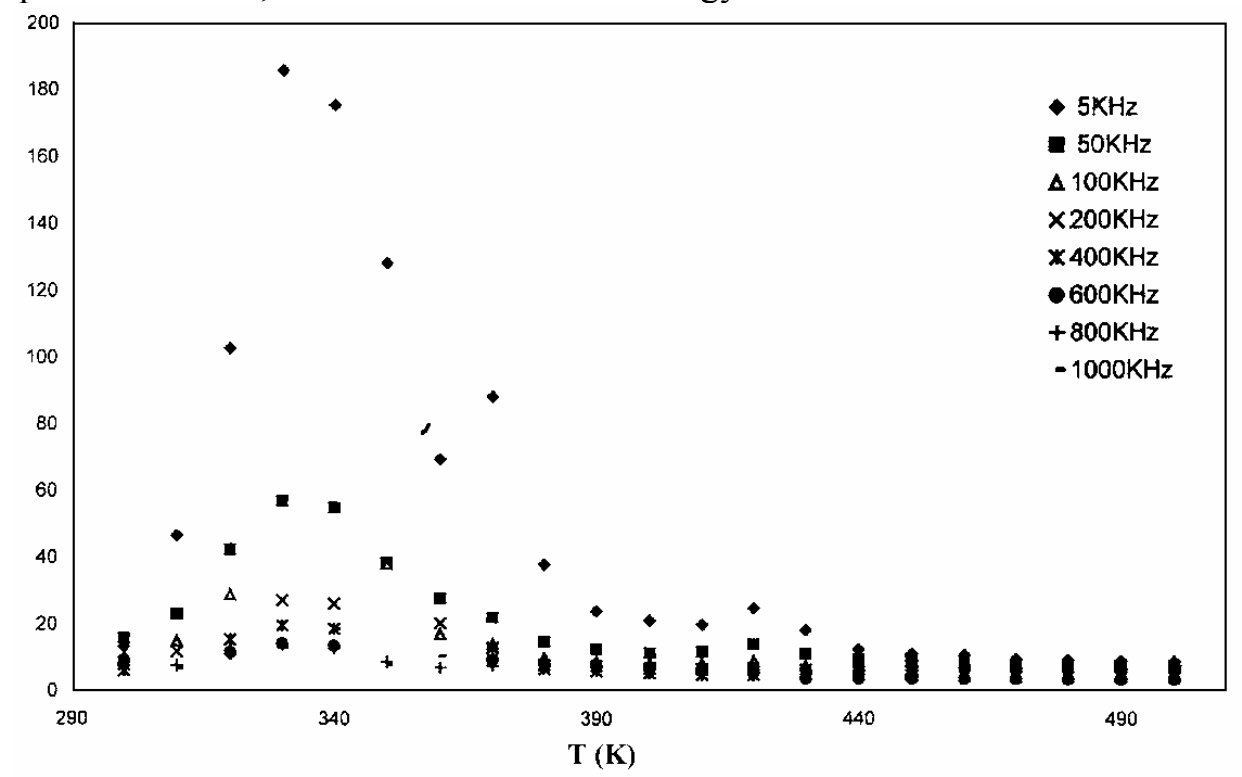

Fig. (3): Real dielectric constant for the $2.5 \mathrm{wt} \%$ Au/FSM-47 sample as a function of temperature and at different frequencies. 
scattering of the charge carriers. This produces a decrease in the mobility, plarizability and permitivity. It can be seen that $\dot{\varepsilon}$ decreases with increasing frequency, which is the general trend of dielectric materials. This is because the dipoles can not follow up the field variation Fig. (3). The same behaviour was obtained for $\mathrm{Au} / \mathrm{NaY}$ and $\mathrm{Au} / \mathrm{FSM}-27$ samples (not shown).

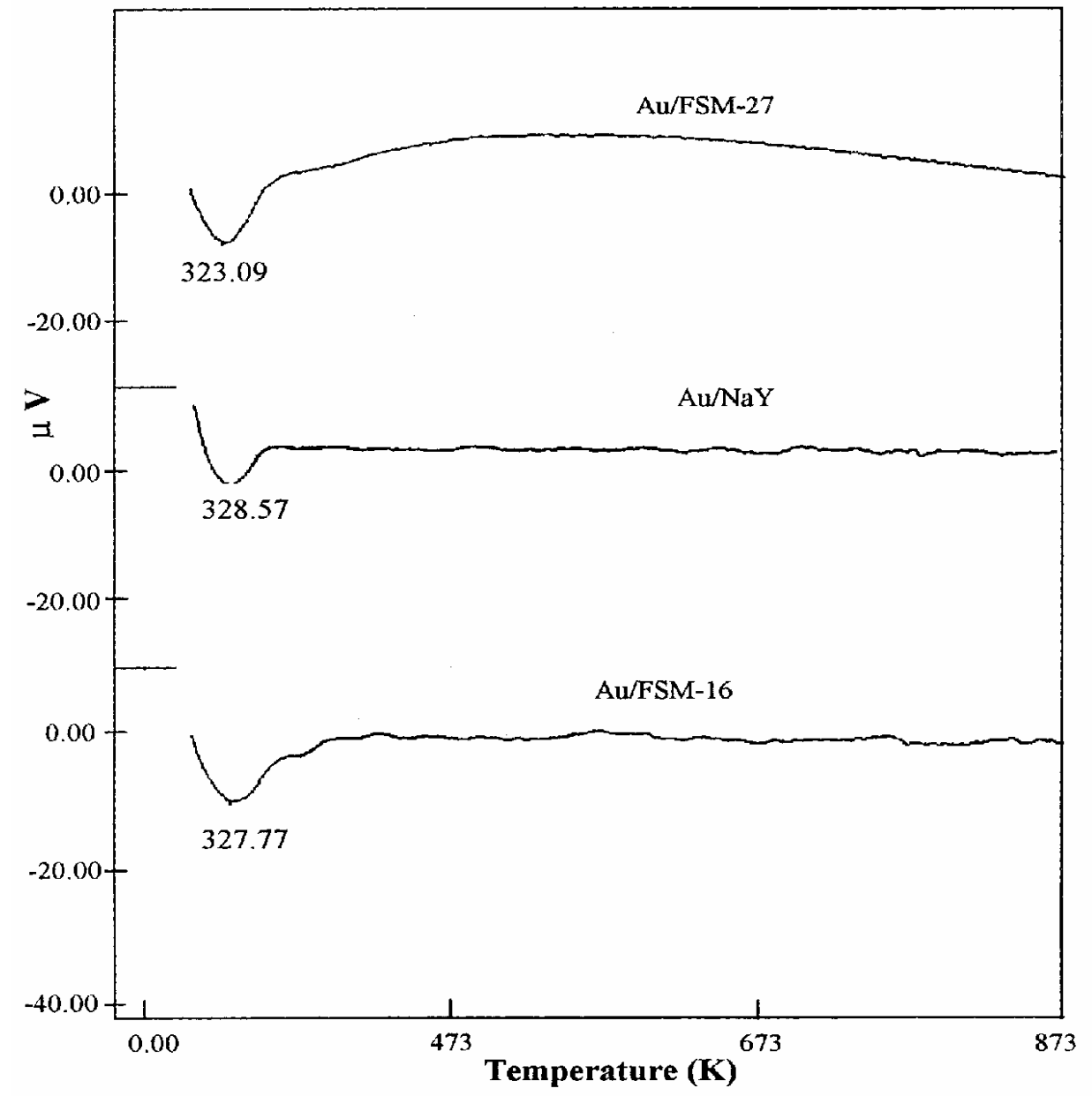

Fig. (4): DTA curves of $2.5 \mathrm{wt} \% \mathrm{Au} / \mathrm{FSM}-27,2.5 \mathrm{wt} \% \mathrm{Au} / \mathrm{NaY}$ and $2.5 \mathrm{wt} \% \mathrm{Au} / \mathrm{FSM}-47$.

Figure (5) shows the IR spectra in the region $3000-1900 \mathrm{~cm}^{-1}$ obtained when an $\mathrm{Au} / \mathrm{FSM}-47$ catalyst is exposed to $\mathrm{CO}$ adsorption, at room temperature, as a function of increasing temperature. The initial spectrum showed a strong band at $2180 \mathrm{~cm}^{-1}$ and a small band at $2128 \mathrm{~cm}^{-1}$. These bands are assigned to the chemisorbed $\mathrm{CO}$ onto $\mathrm{Au}^{+} / \mathrm{FSM}-47$ and $\mathrm{Au}^{0} / \mathrm{FSM}-47$, respectively, as they coincide with those reported for $\mathrm{CO}$-coordinated $\mathrm{Au}-\mathrm{NaY}$ [11]. It can be seen that the $2180 \mathrm{~cm}^{-1}$ band has considerably diminished after raising the 
temperature to $323 \mathrm{~K}$, indicating a substantial decrease in the $\mathrm{Au}^{+}-\mathrm{CO}$ species. Thus, an observed decrease in the relative intensity of $\mathrm{Au}^{+}-\mathrm{CO} / \mathrm{Au}^{0}-\mathrm{CO}$ with temperature was obtained.

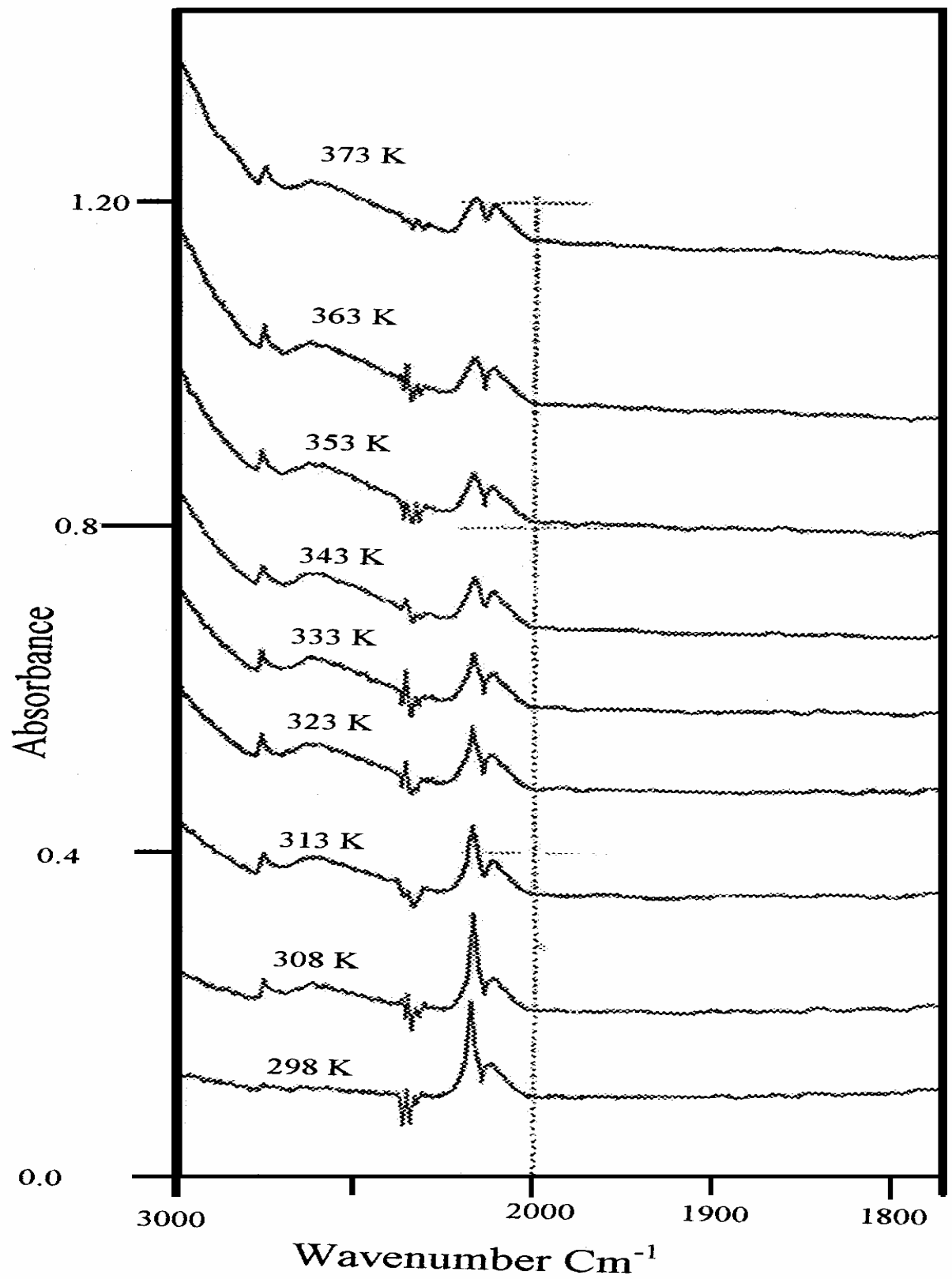

Fig. (5): In situ FTIR spectra of CO adsorption at room temperature on the $2.5 \mathrm{wt} \%$ $\mathrm{Au} / \mathrm{FSM}-47$ sample as a function on increasing temperature. 


\section{Conclusions:}

It has been proven that dual $\mathrm{Au}^{+}$and $\mathrm{Au}^{0}$ sites was responsible for the high conductivity values of $\mathrm{Au}$ when encapsulated inside $\mathrm{NaY}$ zeolite rather than in FSM-27 and FSM-47 zeolite like materials. In addition, the presence of $\mathrm{Na}^{+}$ions of lower ionization energy than that of $\mathrm{Cl}$ ones; in $\mathrm{Au} \mathrm{Cl}_{3}$, were also responsible for enhancing the conductivity of the former than those of the latter. More specifically, the presence of $\mathrm{Au}^{+}$sites evoked the general trend of dielectric materials for $\mathrm{Au} / \mathrm{zeolites}$ in the temperature range from room temperature

to $323 \mathrm{~K}$. Whereas $\mathrm{Au}^{0}$ produced the metallic behaviour beyond the temperature of $323 \mathrm{~K}$. These results were consistent with those obtained from DTA and FTIR techniques.

\section{References:}

1. J. C. Dyre and T. B. Schroder, Rev. Modern Physics 72(3), 873 (2000).

2. D. L. Sidebottom, Phys. Rev. Lett. 82, 3656 (1999).

3. A. S. Md. S. Rahman, M. H. Islam, C. A. Hograth, Int. J. Electron 62, 167 (1987).

4. W. Wackawek, M. Kulesza, M. Zabkowska, Matter. Sci. 7, 385 (1981).

5. A. Goswami, A. P. Goswami, Thin Solid Films 16 (1973) 175.

6. S. I. Shihub, R. D. Gould, phys. status solidi (a) 139, 129 (1993).

7. C. Hamman, Phys. Status Solidi (a) 26, 311 (1968).

8. S. R. Elliot, Philos. Mag. 36, 1291 (1977).

9. G. E. Pike, Phys. Rev. B 6, 1572 (1972).

10. M. M. Mohamed, T. M. Salama, R. Ohnishi, M. Ichikawa, Langmuir 17, 5678 (2001).

11. M. M. Mohamed, M. Ichikawa, J. Colloid and Interface Sci. 232, 381 (2000).

12. M. Haurta, N. Yamada, T. Kobayashi, S. Iijima, J. Catal. 115, 301 (1989). 